\title{
Aspectos psico-sociales de la institución escolar
}

\author{
Luis Rubilar S. 1
}

\section{RESUMEN}

La dialéctica relación entre la microestructura individual y la macroestructura social se mediatiza y vehiculiza a través de formaciones sociales específicas: las Instituciones. Aquí se describen las instituciones educativas, relevando aspectos psico-sociales de su estructura y funcionamiento, especialmente los de índole espacio-temporal, grupal y comunicacional. El análisis se contextúa en el ámbito nacional actual y teniendo como objetivo una mejor comprensión de la relación vincular profesor-alumno.

Palabras claves: Institución escolar; psicología social.

\section{I.- SOCIEDAD-INDIVIDUO-INSTITU- CIÓN EDUCATIVA}

La relación individuo y sociedad constituye una relación compleja y dialéctica en la cual operan factores o instancias intermedias a través de las cuales ella se mediatiza y vehiculiza. El análisis de tales instancias mediadoras resulta esencial dada la basal condición social e histórico-cultural del Hombre, por lo cual son ellas, esas dimensiones contextuales, las que otorgan sentido a la conducta y roles individuales, de modo que su conocimiento constituye un paso imprescindible para comprender la personalidad y las conductas individuales. En el ámbito educativo, esto que para entender y explicar los roles y conductas de profesores y alumnos, la especial relación entre ellos, y los procesos de enseñanza-aprendizaje resulta necesario conocer la situación real y concreta en la cual tales procesos psico-sociales se dan.
El proceso de 'enseñaje' ${ }^{2}$ en el aquí y ahora de la interacción pedagógica, no se agota en lo 'instruccional' ni en la mera aplicación de teorías, principios y leyes del Aprendizaje (en el estilo conductista) sino que, como sabemos, consiste en una situación sui-generis, dialógica y comunicacional, en un contexto social y con una dinámica propia. En tal estructura envolvente, que es institucional y socio-dinámica, es donde debemos ubicar el drama educativo (formal). En tal sentido, el proceso educativo significa una zona decisiva en la que se va reproduciendo, consolidando, innovando y recreando -adecuada o inadecuadamente- el anclaje o nexo psico-social (individuo-sociedad).

Entre el macrosistema social y el microsistema individual van a operar, pues, formaciones sociales, que son organizaciones e instituciones de índole variada, cuyo objetivo consistirá en responder a las distintas necesidades humanas (motivaciones), tanto personales como colectivas. Tales or-

(1) Universidad Metropolitana de Ciencias de la Educación 
ganizaciones sociales, a partir de la familia y la escuela, implican adscripciones casi obligadas para el individuo y su desarrollo personal-social, que le son esenciales para lograr la condición humana. La presencia gradual y múltiple de organizaciones con las cuales se va vinculando genera en la persona sentimientos de identidad y pertenencia; en función de ello va 'aprendiendo' a saber 'quién es' (identidad social). Al mismo tiempo, los grupos a los cuales se va incorporando lo arropan psico-socialmente, otorgándole estatus, seguridad, reconocimiento y finalidad.

Es por esto que la relación individuoinstitución es diádica e interactiva. No es posible una 'institución' sin la presencia del 'factor humano': su substancia y razón de ser, asi como no hay personalidad sin alguna referencia institucional. Para la estructura personal la conexión es de compromiso, en tanto la institución forma parte de la 'organización subjetiva de la personalidad' ('familia interna', tal como se expresa por el niño en test proyectivos).

Esta imbricación o trama 'individuo-sociedad', como todo lo humano, es histórica y tiene antecedentes antropológicos. Desde los modos primitivos, mágicos y sincréticos, de relación vincular (como en los canales y tribus con sus tótems y tabúes) se ha llegado en la actualidad a la proliferación y complejización de las formas de incorporación y comunicación. Según Mayntz: ${ }^{3}$

“nuestra sociedad se caracteriza por la existencia y propagación de formaciones sociales múltiples y complejas, conscientes de sus fines y racionalmente constituidas (hospitales, prisiones, escuelas, empresas, gremios, partidos, universidades). La Organización es una forma de ordenación y un elemento de la dinámica social e influye en la vida individual (encuadramiento social)".

Hay, por lo tanto, instituciones educativas, recreativas, sanitarias, fabriles, comerciales, religiosas, penales, etc.; de ellas, nos interesan aqui las educativas. ${ }^{4} \mathrm{~A}$ través de ellas el sistema global encauza su influencia transmitiendo la Cultura como patrimonio común, preservándola, recreándola y creando nuevas expresiones suyas, siempre en concordancia con los sistemas ideológicos y valóricos imperantes en cada grupo social (nación, por ejemplo). En este sentido, toda I.E. significa un medio de difusión no sólo de mensajes sino de meta-mensajes en términos comunicacionales, los cuales nunca son 'neutros', ya que están teñidos ('currículum oculto') ${ }^{5}$ por la textura ideológico-valórica que sustenta la estructura social en la cual se inserta: en nuestro caso, la ideología neo-liberal, basada en el egoísmo, la competencia y el consumismo. Por estos tiempos, vivimos en Chile la anomia y contradicción entre dos sistemas valóricos contrapuestos, este sistema impuesto e importado y otro, que preconiza la vigencia de los valores democráticos y de los Derechos Humanos, lo cual se va evidenciando no sólo en la dinámica sociopolítica nacional sino, especialmente, en el propio sistema educativo. Son frecuentes, en consecuencia, las 'disonancias actitudinales', los 'dobles estándares o discursos', la disgregación entre teoria y praxis, especialmente en el ámbito del ejercicio de la autoridad y en la conducta cotidiana en el aula escolar.

Por otro lado, en la medida en que 'saber es poder' -y cada vez más en una 'sociedad del conocimiento-, la l.E. va segregando y con ello consolidando las diferencias de clases en la sociedad, basada en una jerarquía social. Experiencias como la del Padre Miliani en Italia (1972 -Escuela de Barbiana), los datos entregados por organismos internacionales, o los propios que conocemos en Chile, tales como distribución del ingreso, niveles de pobreza, resultados del Simce y arbitrariedad de la PAA, cobertura restringida y selectiva de las Is.Es. 'privadas', no hacen sino confirmar el papel selectivo que cumple la I.E., de tal modo que la 'mejor' educación se entrega a la clase social alta, y a los niveles más deprivados apenas la básica-media, sin poder acceder a formaciones más rele- 
vantes, dado el actual Sistema de Educación Superior. Una Psicología concreta no puede prescindir de tales contextos situacionales, por lo cual debe procurar la investigación y conocimiento de las condiciones de vida y características del medio familiar-escolar en que se desarrollan los aprendizajes psico-sociales del estudiante chileno, de cualquier nivel.

\section{II.-CARACTERÍSTICAS DE LAS INSTITUCIONES}

Las instituciones, en tanto formaciones sociales, se definen según sus finalidades $u$ objetivos, los cuales condicionarán la estructura y la dinámica, las interrelaciones y actividades que cada institución articula y realiza. Serán tales objetivos los que demarcarán las diferencias inter-institucionales; de ellos dependerá su estructura (organigrama) y sus funciones específicas. ${ }^{8}$

Hay elementos estructurales que son comunes a toda Institución:

\section{Lugar y espacio compartidos.}

Objeto (lo que ocupa a la institución).

Sistema de estatus y roles: tareas, jerarquía, responsabilidades; expectativas y conductas pautadas de rol.

Sistemas de comunicación: horizontales-verticales, internos-externos, formalesinformales.

Personas: criterios de reclutamiento, permanencia -ligados a premios y castigos-, reglamentos normativos.

Objetivos, que le otorgan racionalidad y dirección.

Al poseer la Institución-continente tales características pasa a otorgar al individuo que le integra:

cierta circunscripción en el espacio cierta distribución de su tiempo distribución de sus funciones y responsabilidades cierto sistema y código de comunicación un objetivo y finalidad.

No se trata de que tales directividades y distribuciones consistan en elementos meramente objetales o externos: lo importante es que ellas se internalizan, conformando parte de la cultura y personalidad subjetiva de cada integrante; en alto grado va siendo su espacio, su tiempo, su función, su vida. La psicología organizacional concede importancia a este 'compromiso' o involucración personal respecto a las instituciones a las cuales los individuos se adscriben, especialmente dada su significación en el área laboral (Ergonomía). ${ }^{7}$ De aquí la emergencia de logotipos, poleras, agendas, incentivos, símbolos de identidad institucional, equivalentes a nuestro criollo 'ponerse la camiseta'. El difícil equilibrio entre la autonomía del desarrollo y estructura personales y la omnipresencia internalizada de lo institucional, es caldo de cultivo para múltiples conflictos de identidad, de roles y de relaciones humanas. De algún modo, toda Institución tiende a rigidizar (encapsular, consagrar) al individuo en su rol, y de aquí, también, el riesgo de 'burocratización', de enmascaramiento, de abusos de poder, de 'violencia simbólica', de competitividad exagerada a que está expuesto, en nuestro caso, el Profesor, al cumplir con su rol formal en la institución escolar.

En el mundo social existen algunas instituciones que, por sus especiales características, se las denomina instituciones totales $^{8}$; si bien toda Institución absobe parte del tiempo e interés de sus miembros y les proporciona algo así como un 'mundo propio', en el caso aludido dicha absorción es completa: así en los Hogares, Hospitales, cuarteles, internados, cárceles, donde se transforma' a las personas, dándose un proceso de mortificación y agresión al yo (violación de sus límites, de su espacio personal), sea o no aceptado voluntariamente. Se produce el despojo de la individualidad y libertad personales que logra su expresión macrosocial en las dictaduras autocráticas, de todo tipo. 
Es importante vislumbrar esta otra dimensión -extrema- de las instituciones ya que en el campo educacional, si bien teóricamente tales situaciones no debieran darse, de hecho, histórica y contemporáneamente, se dan con diversos matices y grados (caso 'escuelascárceles', caso Colonia Dignidad, sectas religiosas, etc.).

\section{III.-EDUCACIÓN Y GRUPO INSTITUCIONAL}

Toda institución, por su condición social, consiste en una formación grupal, significativa y comunicacional. En tanto 'grupo', une y encadena lo heterogéneo (personalidades), constituyéndose en 'conjunto' (gestalt) que opera como referente práctico diferenciado (de otros grupos). ${ }^{9}$

En términos genéricos, esta variable intrainstitucional -grupo-implica: a) dos o más personas, pluralidad, conjunto; b) comunicación, interacción, ligazón, interdependencia, vínculo; c) coparticipación en normas, constantes de espacio-tiempo; d) ejercicio de roles complementarios, ye) objetivos comunes (expectativas, tareas, metas).

En la estructura escolar el grupo-curso consiste en una configuración formal y secundaria, de índole operacional o de trabajo, con modalidades particulares respecto a roles, normas, cohesión y comunicación, en la cual el Profesor 'no trata sólo con individuos aislados, sino con un grupo de personas, organizadas en una estructura social'. Una descripción más exhaustiva de este importante escenario formativo en que se produce el vínculo psico-pedagógico nos la ofrecen Bany Johnson: ${ }^{10}$

"Un grupo de clases es una organización social y por naturaleza también una agrupación psicológica. Es un grupo social al estar formalmente organizado (en cuanto a propósitos, tareas y metas del grupo). Es psicológico en la medida en que la interacción de unos individuos con otros desarrolla tipos adicionales de experiencia (grupos informales)...es un grupo de trabajo...Sus características distintivas son: a)la meta o finalidad para la cual se ha reunido es para aprender; b) la participación en el grupo es obligatoria, asi como las metas; c) los miembros del grupo no tienen derecho a la elección del jefe o influencias que son percibidas por sus integrantes. El grupo de clase es único en su finalidad que es organizar la producción de cambios en los miembros del grupo...Sus integrantes son más homogéneos que en otros grupos (edad semejante, intereses análogos, necesidades y deseos similares, etc.). Cada sala de clases constituye un sub-sistema separado dentro de la escuela. Las posiciones (estatus-roles) están interrelacionados, se refuerzan entre sí $y$ son interdependientes...".

Como en toda organización social se produce aquí el llamado clima (atmósfera) social, generando distintos estilos de liderazgos: autocrático, democrático, laissezfaire (K.Lewin), según los cuales se puede facilitar, interferir y/o impedir el logro tanto de los objetivos del grupo de aprendizaje como de la institución misma. Para aportar en resolver problemas referidos a esta dimensión integrativa han surgido técnicas de dinámica y manejo de grupo en términos de análisis y acción, tanto terapéuticas como psico-pedagógicas (J.L. Moreno, M. Gibb, J. Maisonneuve, C. Rogers, entre otros).

La organización social de la l.E. puede ser: a) formal (organigrama), según sistema de roles y normas que responden más que a satisfacer necesidades individuales, a lograr los objetivos colectivos, por lo cual se trata de un nivel ordenador, disciplinario, estructurador; su exageración normativa (reglamentos, prohibiciones, coacciones) potencialmente pueden gatillar actitudes de apatía, pasividad, sometimiento e intimidación, agresividad u hostilidad entre sus miembros; b) informal: más proclive a satisfacer necesidades personales y de sub-grupos, por lo cual es más creativa y gratificante en lo inmediato. Puede generar afi- 
liaciones, adhesiones afectivas y cohesión grupal elevadas, emergiendo correlativamente liderazgos informales. Si se produce una complementación adecuada y sinérgica entre ambas modalidades organizativas -formal e informal-, se potencian y hacen posibles incrementos del sentimiento de pertenencia y cohesión, lo cual redunda en una mejor realización de las tareas y metas.

\section{IV.-EDUCACIÓN Y COMUNICACIÓN}

El 'enseñaje' implica una situación dialógica e interactiva, que supera la mera trasmisión unidireccional o el adiestramiento instruccional (información o educación 'bancaria'- P. Freire-) y que, por tanto, involucra una compleja trama de interacción múltiple en una situación sociodinámica concreta. Entendiendo, en una primera aproximación, Aprendizaje como 'producción o modificación más o menos estable de pautas de conducta, ${ }^{11}$ para que se genere intervienen variadas variables comunicacionales, tales como: emisor, mensaje, receptor, retroalimentación, código, símbolo, medio, semántica, metacomunicación o (metamensaje), etc., con predominancia de lo interpersonal y grupal.

En la medida en que todo sistema educacional (formal) posee una intencionalidad formativa y de transmisión cultural, opera fundamentalmente con significados ( $2^{\circ}$ sistema de señales, en términos pavlovianos), los cuales deben comunicarse aquí intergeneracionalmente. Para cumplir plenamente la intercomunicación ayudan enormemente la presencia de 'redes', el 'clima grupal', el tipo de liderazgo y la utilización de técnicas grupales El efecto de la 'comunicación pedagógica' dependerá, además, de condiciones coadyuvantes como la motivación de sus integrantes, la calidad efectiva de los vínculos, el género, la empatía, la ausencia de interferencias, la cantidad de integrantes, etc. ${ }^{12}$.

Es relevante aquí el papel de la comu- nicación verbal (lenguaje) ya que el proceso psicopedagógico se produce sustento en la cultura alfabético-fonética; sin embargo, son importantes, también, los papeles jugados por: a) la comunicación no-verbal (proxemia, kinesia, paralingüística) y b) los aportes de la cultura electrónica-visual, con la hegemonía del mensaje icónico (visual) que no sólo invade el espacio escolar sino, además, el espacio vital y cotidiano en que crece y se desarrolla el estudiante. Tal avance de la cultura de la imagen obligará, en corto plazo, a readecuar metodologías y didácticas específicas (entre ellas, los textos) a las exigencias de tal cultura, con sus inéditos espacios virtuales (ciber-espacio). Los recursos audiovisuales, especialmente los computarizados, a la vez que facilitan, también hacen más compleja la variable comunicacional en el proceso de formación humana en que consiste la Educación. Lo importante, tal vez, es tener presente que tales técnicas son instrumentos para aprender y mejor vivir, y no fines en sí mismos, en tanto el fin primero y último de la educación es la persona y su interacción con la sociedad.

Esta especie de supraestructura tecnológica que cruza como capa la superficie terrestre, las calles, las unidades escolares y hogares (satélites, hilos, cables, cordones, antenas, carreteras), transmitiendo mensajes múltiples, está significando un bombardeo permanente de estímulos e imágenes que gestan en los receptores multiaprendizajes, ya no como tratos senso-perceptuales directos, sino aprendizaje vicariantes, los cuales no siempre se compatibilizan con los que habitual y expeniencialmente son asimilados y acomodados en la vida concreta y real del estudiante. Esto produce disonancias y desajustes, tanto en la estructura interna personal como en la 'cultura escolar'(formal) y la cultura cotidiana en la que está inmerso el alumno, en el medio ambiente extra-escolar. A esta disonancia y anacronismo entre la cultura subjetiva que trae el estudiante y la programación formal que le ofrece la I.E. con sus objetivos numerados y su eva- 
luación 'objetiva' se suma, además y muy decisivamente, la anomia valórica ofertada seductoramente por la televisión, por ejemplo, con sus 'telenovelas', 'best-sellers' y 'spots publicitarios', instrumentados al servicio de la ideología mercantil y consumista impuesta por un sector de adultos que maneja el poder, conllevando desestabilizaciones psico-sociales, frustraciones juveniles,alienaciones e idolatrías espúreas, confusiones y desesperanzas, en síntesis, un lamentable cuadro de difusión de identidad personal y social, cuyos efectos tienen difícil pronóstico.

En el ámbito educacional, todo esto tiene manifestaciones específicas, catalogadas como disgregación y desorientación, síndromes amotivacionales, déficits atencionales, bajos rendimientos, pugnas emotivas y contradicciones vitales, dadas sus características etarias, que muchas veces la institución escolar no está en condiciones de solucionar o superar, más aún cuando los contenidos y mensajes estriban en áreas críticas como la sexualidad, la violencia y agresividad, la competencia y lucro económicos, el egoísmo y heroicidad individualistas o el poder y la gloria, formateados e importados desde otros referentes culturales, distintos a los de nuestros países latinoamericanos y a los que vive diariamente nuestro pueblo, especialmente su niñez y juventud.

\section{V.- LA RELACIÓN VINCULAR PROFESOR-ALUMNO}

Es en este escenario con sus coordenadas espacio-temporales, organizacionales, comunicacionales y grupales, que se produce la relación vincular profesor-alumno, por lo cual ella se lleva a cabo: i) en un contexto socio-institucional; ii) supeditada y recargada por determinaciones de índole ideológica y moldeada según el patrón de relaciones sociales que imperan en el sistema socio-económico y contexto cultural vigentes, y iii) en forma preestablecida acorde con la prescripción de roles.
En nuestro país, por ejemplo, a través de algunas medidas de reforma se pretenden modificar tales variables: ampliación de locales y material de apoyo logístico, mayor permanencia del estudiante en la institución, superación de los modos frontales y memorísticos de trabajo docente, logro de participación más activa y autónoma tanto de las unidades educativas como de sus integrantes en la toma de decisiones. Obviamente, las dificultades se presentan no sólo en la sustentación económica, sino en la modificación de actitudes por parte de alumnos y profesores, y la comunidad toda, ya que los rasgos definitorios han venido siendo en cuanto al rol 'alumno', de dependencia, pasividad, sometimiento y subordinación. Tal estereotipo y expectativa de rol es el que efectivamente rige intrainstitucionalmente en el aula escolar, en sus diversos niveles:

"En la enseñanza, sea cual sea la concepción de liderazgo, el vínculo natural es el de la dependencia (el profesor sabe más, debe proteger, legitimar los intereses, definir la comunicación, etc.). Es él quien pacta el tiempo, el espacio y los roles de relación. Es el profesor para los alumnos una autoridad que, además enseña, de la misma manera que para el profesor el alumno es un subordinado que, además, aprende"..$^{13}$

Como secuelas de tal escastramiento relacional se producen trabas y dificultades en el proceso de desarrollo personal-social (autorrealización), agravadas por el hecho de que tales relaciones asimétricas rigen en el nivel macrosocial (patrón-empleado, hombremujer, adulto-joven) y sociopolítico (cúpulas dirigentes, no participación ciudadana, manipulación informativa). Muchos investigadores cientistas-sociales y pedagogos (P.W. Jackson, P.Bourdieu) coinciden en señalar que la I.E. tiende a reproducir el orden establecido, bloqueando y controlando la creatividad, domesticando y condicionando al estudiante en función de los intereses (currículum oculto) político-ideológicos y económicos del sistema neoliberal. 
En Chile, tal situación constrictiva y limitante se hizo crítica en la etapa dictatorial, durante la cual se permeó la comunicación educacional de actitudes de sospecha, represión y discriminación política y socio-económica. Afortunadamente la larvada redemocratización nacional, acorde con pautas socio-culturales innovadoras, ha ido gestando la emergencia, por una parte, de la significación de los Derechos Humanos y , por otra, de temas cruciales para el desarrollo democrático como son los de integración, género, equidad o educación permanente. Todo ello va modificando, gradualmente, a su vez, los modos de comunicación intrainstitucionales, permitiendo mayor participación y nuevas formas de vinculación, más cooperativas y solidarias. En este contexto, en lo educacional, se tiende a relevar no sólo la dimensión intelectual sino, también, la afectiva y social, en términos de una formación más holística e integral. Sin embargo, en la práctica cotidiana persiste el modelo autoritario y la prevalencia de lo cognitivo, así como en la rutina institucional se evidencia una profunda dicotomía entre el discurso y la praxis, reforzando todo ello por el hecho de que no existe explícitamente una Filosofía y Política educacional que guíe y oriente el sistema integral. Se imponen poderes fácticos e intereses económicos y competitivos, prioritariamente funcionales al modelo neoliberal legado por el régimen autocrático.

La Educación, y sus disciplinas fundantes o auxiliares, como la Psicología Educacional, precisan tener como referente un modelo de sociedad para el cual se forme el futuro ciudadano y hacia el cual debe converger la intencionalidad educativa: la jerarquía de valores y deberes cívicos, la formación de actitudes, destrezas y competencias, la identidad psicosocial y nacional, según las cuales insertar el mensaje permanente de la institución y del quehacer comunitario. Pensamos que es tarea nuestra, de los educadores y psicólogos educacionales, profundizar y socializar la democratización del país, tarea que, para el profesor -por su misión-, debiera implicar un com- promiso mayor: no sólo democratizar las estructuras de poder y la injusta distribución del ingreso nacional, sino la de todas las formas de relación y modos de comunicación (interindividuales e intergrupales), en conformidad con los valores ínsitos en los Derechos Humanos individuales, sociales, económicos, políticos y culturales. En tal sentido, consideramos fundamental tener claro: a) que 'la democracia no puede aprenderse o enseñarse antidemocráticamente', y b) que la Economia (productividad) debe estar al servicio del Hombre -y de las mayorías- y no el Hombre -y las mayorias- al servicio de lo económico -y la minoría-, como se vislumbra en los criterios dictaminados en la Constitución Política (1980) y en la L.O.C.E. (1990) e, incluso, en algunos dispuestos por los propios gobiernos democráticos posteriores cuando exponen el patrimonio nacional a privatizaciones en nombre de la panacea llamada 'modemización'.

Todo este cúmulo de significados, mensajes y valores se articulan sincréticamente en el denso espacio grupal y comunicacional que es toda I.E. y toda experiencia de aula: es aquí y con todo esto que se va produciendo el aprendizaje, fenómeno psico-social y socio-educacional que, desde la perspectiva 'constructivista'14, que opera a partir de una primaria secuencia interpsicológica para convertirse en fenómeno intrapsicológico. Todo lo cual viene a confirmar que dicho proceso no se gesta ni produce aislado, en abstracto, segregado del mundo concreto y simbólico en el cual está inserto el aprendiz y el profesor, sino en situación dialógica e interactiva en que se conjugan todas las variables psicosociales aludidas. En este ámbito de significado tiene pleno sentido la invocación que nos dejara el latinoamericanista educador para la práctica de la libertad, nuestro recién ido Paulo Freire:

"Lo que queremos es una pedagogía que admita la espontaneidad, el sentimiento y la emoción, y que acepte como punto de partida lo que yo llamaría el 'aquí y ahora', perceptivo, histórico y social de los alumnos..." 


\section{REFERENCIAS}

1 Tal relación ha sido desarrollada, en términos teóricos, entre otros, por: K. Kosic, Dialéctica de lo concreto, Grijalbo, Méx., 1975; P. Watzlawick, Teoría de la comunicación humana, Herder, Barcelona, 1984; P. Bergerth.Luckmann, La construcción social de la realidad, Amorrortu, Bs.As., 8a., 1989; M. Montero (Coord.), Construcción y crítica de la psicología social, Anthropos, Caracas, 1994; H. Maturana, El sentido de lo humano, Dolmen, Santiago, 7a, 1995.

J.. Bléger ha acuñado este neologismo que grafica bien la interrelación de los procesos de enseñanza y aprendizaje. Ver Temas de Psicología (Entrevista y grupo), Nueva Visión, Bs.As., 1974 (p.61).

1 Universidad Metropolitana de Ciencias de la Educación. fono 2392522 anexo 430.

3 en Sociología de la organización, Alianza, Madrid, 1972, (cap. l)

4 Maldavsky-Boffa describen así la l.E.: "grupo humano abocado a una tarea, en tiempo y espacio limitados, que sustenta un objetivo manifiesto: trasmitir cultura; organizado jerárquicamente, con códigos comunicacionales y normativos específicos, y en interrelación constante con la comunidad o contexto social". ('El rol del psicólogo educacional en la institución escolar', en Rev. Argentina de Psicología, T. I, № 2, 1969).

5 Ver: P.W. Jackson, La vida en las aulas, Morata, Madrid, 4a., 1991, y J. Torres, El Currículum oculto, Ed. Morata, Madrid, 4a., 1994.

6 Sobre psicología institucional ver: PravazTroya, 'Psicología institucional: algunos conceptos básicos', en Rev. Argentina de Psicología, Año I, № 2,1969; D.H. Johnson, Psicología social de la educación, Kapelusz, Bs.As. 1970; G. Michaud, Análisis institucional y Pedagogia, Laia, Barcelona, 1972; R. Lourau, El análisis institucional, Amorrortu, Bs.As., 1975; R. Lourau-G. Lapassade, Análisis institucional y socioanálisis. Nueva Imagen, Méx., 1977; D.
Katz-R.Khan, Psicología social de las organizaciones, Trillas Méx., 1977; J. Whittaker, La psicología social en el mundo de hoy, Trillas Méx.., 1980; S. Robbins, Psicología de las organizaciones, Prentice Hall, Méx., 1987; J. Palacios (Comp.), La cuestión escolar, Fontanara, Méx., 1995; T.L. Good-J. Brophy, Psicología educativa contemporánea (Parte VI), Mc GrawHill, Méx., 5a., 1996.

7 VerA. Wisner, Ergonomía y condiciones de trabajo, Humanitas, Bs.As., 1988.

8 Ver E. Goffman, Internados. Ensayo sobre la situación de los enfermos mentales, Amorrortu, Bs. As., 1970.

9 E. Pichón-Riviére, el creador de los 'grupos operativos', define grupo como "conjunto restringido de personas ligadas entre sí por constantes de espacio-tiempo, articulados por su mutua representación interna, que se proponen en forma explícita o implícita una tarea que constituye su finalidad" (en El proceso grupal, Nueva Visión, Bs.As, 1977, p. 209).

10 en La dinámica de grupos en la educación, Aguilar, Madrid, 1973, pp. 41-57.

11 J. Bléger,op. cit., p. 63.

12 Ver M. Salazar, Psicología Social, Trillas, Méx., 1980 (especialmente caps. II y VII); E. Rogersotro, La comunicación en las organizaciones, Mc. Graw-Hill, Méx., 1980, y F. Simonetti, Comunicación efectiva (Psicología de la comunicación humana), PUC, Santiago, 1987.

13 R. Boholavsky, 'Psicopatología del vínculo profesor-alumno: el profesor como agente socializante, en Revista de Ciencias de la Educación, Año II, N² 6, 1971, Bs.As., Argentina.

14 Ver, L. Vygotsky, otros, El desarrollo de los procesos psicológicos superiores, Grijalbo, Barcelona, 1979; C. Coll, Psicología y cumculum, Paidós Méx.., 1992; P. Aznar, otros, Constructivismo y Educación, Tirant lo Blanch, Valencia, España, 1992, y C. Coll, J. Palacios, A. Marchesi, Desarrollo Psicológico y Educación-ll (Psicología de la Educación- Caps. 6 y 23), Alianza, Madrid, 5a., 1993. 